\title{
Effects of fucoidan on proliferation, AMP-activated protein kinase, and downstream metabolism- and cell cycle-associated molecules in poorly differentiated human hepatoma HLF cells
}

\author{
TAKUMI KAWAGUCHI ${ }^{1,2}$, MASAKO HAYAKAWA ${ }^{2}$, HIRONORI KOGA ${ }^{1,2}$ and TAKUJI TORIMURA ${ }^{1,2}$ \\ ${ }^{1}$ Division of Gastroenterology, Department of Medicine, Kurume University School of Medicine; \\ ${ }^{2}$ Liver Cancer Division, Research Center for Innovative Cancer Therapy, Kurume University, Kurume, Japan
}

Received January 25, 2015; Accepted February 27, 2015

DOI: 10.3892/ijo.2015.2928

\begin{abstract}
Survival rates are low in patients with poorly differentiated hepatocellular carcinoma (HCC). Fucoidan, a sulfated polysaccharide derived from brown seaweed, has anticancer activity; however, the effects of fucoidan on poorly differentiated HCC remain unclear. In this study, we investigated the effects of fucoidan on AMP-activated protein kinase (AMPK), a proliferation regulator, and its downstream metabolismand cell cycle-related molecules in a poorly differentiated human hepatoma HLF cell line. HLF cells were treated with fucoidan $(10,50$, or $100 \mu \mathrm{g} / \mathrm{ml} ; \mathrm{n}=4)$ or phosphate buffered saline (control; $n=4$ ) for $96 \mathrm{~h}$. Proliferation was evaluated by counting cells every $24 \mathrm{~h}$. AMPK, TSC 2 , mTOR, GSK3 $\beta$, acetyl-CoA carboxylase (ACC), ATP-citrate lyase, p53, cyclin D1, cyclin-dependent kinase (CDK) 4, and CDK6 expression and/or phosphorylation were examined by immunoblotting $24 \mathrm{~h}$ after treatment with $100 \mu \mathrm{g} / \mathrm{ml}$ fucoidan. Cell cycle progression was analyzed by fluorescence-activated cell sorter $48 \mathrm{~h}$ after treatment. Treatment with 50 or $100 \mu \mathrm{g} / \mathrm{ml}$ fucoidan significantly and dose- and time-dependently suppressed HLF cell proliferation $(\mathrm{P}<0.0001)$. Fucoidan induced AMPK phosphorylation on Ser172 $24 \mathrm{~h}$ after treatment. Although no
\end{abstract}

Correspondence to: Dr Takumi Kawaguchi, Division of Gastroenterology, Department of Medicine, Kurume University School of Medicine, 67 Asahi-machi, Kurume 830-0011, Japan

E-mail: takumi@med.kurume-u.ac.jp

Abbreviations: HCC, hepatocellular carcinoma; AMPK, adenosine monophosphate-activated protein kinase; p, phosphorylated; TSC, tuberous sclerosis complex; mTOR, mammalian target of rapamycin; eEF, eukaryotic elongation factor; eEF2K, eukaryotic elongation factor 2 kinase; GSK, glycogen synthase kinase; ATP, adenosine triphosphate; ACL, ATP-citrate lyase; ACC, acetyl-CoA carboxylase; $\mathrm{Rb}$, retinoblastoma; CDK, cyclin-dependent kinase; GAPDH, glyceraldehyde-3-phosphate dehydrogenase; PBS, phosphate buffered saline

Key words: fucoidan, hepatocellular carcinoma, AMP-activated protein kinase, cyclin D1, acetyl-CoA carboxylase differences were seen in expression and phosphorylation levels of TSC2, mTOR, GSK3 3 , ATP-citrate lyase, and p53 between the control and fucoidan-treated HLF cells, fucoidan induced ACC phosphorylation on Ser79. Moreover, fucoidan decreased cyclin D1, CDK4 and CDK6 expression $24 \mathrm{~h}$ after treatment. Furthermore, HLF cells were arrested in the G1/S phase $48 \mathrm{~h}$ after fucoidan treatment. We demonstrated that fucoidan suppressed HLF cell proliferation with AMPK phosphorylation. We showed that fucoidan phosphorylated ACC and downregulated cyclin D1, CDK4 and CDK6 expression. Our findings suggest that fucoidan inhibits proliferation through AMPK-associated suppression of fatty acid synthesis and G1/S transition in HLF cells.

\section{Introduction}

Hepatocellular carcinoma (HCC) is a common cancer with high morbidity and mortality rates (1). Although prognosis of patients with HCC has improved due to the development of techniques for early detection and treatment, the overall survival rates in patients with poorly differentiated HCC remain low (2).

Fucoidan is a water-soluble dietary fiber derived from brown seaweed. It is composed of polysaccharides containing L-fucose and sulfate ester groups (3). Fucoidan has various biological activities including anti-inflammatory, anti-viral and antihypertensive actions $(4,5)$. Furthermore, fucoidan exerts anticancer activity and is reported to inhibit the proliferation of colon, breast and prostate cancer cell lines (6-8). Although fucoidan suppresses HCC proliferation, most of the cell lines used in previous studies, including HepG2 and Huh-7 cells, were well-differentiated (9-14). Thus, the anticancer activity of fucoidan against poorly differentiated HCC cells, such as the HLF cell line, remains unclear.

The mechanisms of fucoidan-mediated hepatoma inhibition have been investigated. However, Zhu et al reported that fucoidan does not inhibit vascular endothelial growth factor, basic fibroblast growth factor, interleukin-8, or heparanase expression in HCC cells and/or tumor tissues, and that it had no effect on angiogenesis and apoptosis in vivo (12). Thus, the mechanisms of fucoidan-mediated hepatoma inhibition remain unclear. Adenosine monophosphate-activated protein 
kinase (AMPK) is a sensor of cellular energy and nutrient status and can crosstalk with signaling pathways that promote proliferation (15). Activated AMPK regulates molecules associated with protein, glucose and lipid metabolism and the cell cycle, thereby suppressing cancer proliferation $(16,17)$. However, the effects of fucoidan on AMPK and its downstream molecules are unknown.

The aim of this study was to investigate the effects of fucoidan on the proliferation of the poorly differentiated HCC cell line HLF. Additionally, we examined the effects of fucoidan on AMPK and its downstream metabolism and cell cycle-associated molecules in HLF cells.

\section{Materials and methods}

Reagents and antibodies. Fucoidan from Fucus vesiculosus was purchased from Sigma-Aldrich Co. LLC (St. Louis, MO, USA). All other reagents were purchased from Wako Pure Chemical Industries, Ltd. (Osaka, Japan) unless otherwise indicated. Antibodies against AMPK, phosphorylated (p)-AMPK (Thr172), tuberous sclerosis complex (TSC) 2, p-TSC2 (Thr1462), mammalian target of rapamycin (mTOR), p-mTOR (Ser2448), p-eukaryotic elongation factor (eEF) 2 (Thr56), eukaryotic elongation factor 2 kinase (eEF2K), p-eEF2K (Ser366), glycogen synthase kinase (GSK) $3 \beta$, p-GSK3 $\alpha$ (Ser21), p-GSK3 $\beta$ (Ser9), adenosine triphosphate (ATP)-citrate lyase (ACL), p-ACL (Ser454), acetyl-CoA carboxylase (ACC), p-ACC (Ser79), retinoblastoma (Rb), p16, p53, p-p53 (Ser9), p-p53 (Ser15), cyclin D1, cyclin-dependent kinase (CDK) 4, CDK6 and glyceraldehyde-3-phosphate dehydrogenase (GAPDH) were purchased from Cell Signaling Technology, Inc. (Danvers, MA, USA). Antibodies against p21 were purchased from BD Biosciences (San Jose, CA, USA).

Cell lines. HLF cells were maintained in Dulbecco's modified Eagle's medium supplemented with $10 \%$ fetal bovine serum (Life Technologies; Japan, Tokyo, Japan), penicillin (100 U/ml) and streptomycin $(100 \mathrm{U} / \mathrm{ml})$ at $37^{\circ} \mathrm{C}$ in a humidified atmosphere containing $5 \% \mathrm{CO}_{2}$.

Fucoidan treatment. HLF cells were seeded ( $1 \times 10^{4}$ cells) in 10-cm dishes. Fucoidan was dissolved in phosphate buffered saline (PBS; $130 \mathrm{mM} \mathrm{NaCl}, 2 \mathrm{mM} \mathrm{NaH}_{2} \mathrm{PO}_{4}$ and $7 \mathrm{mM}$ $\mathrm{Na}_{2} \mathrm{HPO}_{4}, \mathrm{pH} 7.4$ ), and 10,50 or $100 \mu \mathrm{g} / \mathrm{ml}$ of fucoidan was added $2 \mathrm{~h}$ after seeding. The culture medium containing fucoidan was replaced every $24 \mathrm{~h}$, until $96 \mathrm{~h}$.

Cell proliferation analysis. Cell proliferation was evaluated by counting cells. Cells were counted 0, 24, 48, 72 and $96 \mathrm{~h}$ after treatment with fucoidan ( $n=4$ per condition) or PBS (control; $n=4)$. Cells were trypsinized after washing with PBS. Then, cell numbers were determined using an automated cell counter (CDA-500; Sysmex Corp., Kobe, Japan) as previously described (18).

Immunoblotting analysis. After washes with PBS, cells were lysed in lysis buffer (50 mM HEPES, $250 \mathrm{mM} \mathrm{NaCl}$, $20 \mathrm{mM}$ EDTA and $0.1 \%$ Nonidet P-40, pH 7.5) containing $1 \mathrm{mM}$ phenylmethylsulfonyl fluoride, a protease inhibitor cocktail (Sigma-Aldrich Co. LLC.), $10 \mathrm{nM} \mathrm{NaF}$ and $1 \mathrm{mM}$
$\mathrm{Na}_{3} \mathrm{VO}_{4}$. Cell lysates were centrifuged at 12,000 x $\mathrm{g}$ for $20 \mathrm{~min}$ at $4^{\circ} \mathrm{C}$, and the supernatant was collected. The protein concentration was determined by a Bio-Rad protein assay kit (Bio-Rad Laboratories, Inc., Hercules, CA, USA). The samples were then mixed with an equal volume of $2 \mathrm{X}$ sample loading buffer containing $2 \%$ sodium dodecyl sulfate (SDS) and 2-mercaptoethanol, and were incubated at $95^{\circ} \mathrm{C}$ for 5 min. Samples were loaded on SDS-polyacrylamide gels and transferred onto equilibrated polyvinylidene difluoride membranes (Bio-Rad Laboratories, Inc.). The membranes were blocked for $1 \mathrm{~h}$ at room temperature with $5 \%$ skim milk, and then incubated with primary antibodies overnight at $4^{\circ} \mathrm{C}$. The membranes were washed and incubated with horseradish peroxidase-labeled secondary antibodies (GE Healthcare UK Ltd., Buckinghamshire, UK) for $1 \mathrm{~h}$ at room temperature. After several washes, the membranes were incubated with chemiluminescent reagents (ECL Advanced Western Blotting Detection kit; GE Healthcare UK Ltd.), and specific bands were visualized by an image analyzer LAS-1000 plus (Fuji Film, Tokyo, Japan) as previously described (19).

Cell cycle analysis. After treatment with PBS or $100 \mu \mathrm{g} / \mathrm{ml}$ fucoidan for 24 or $48 \mathrm{~h}$, the cells were trypsinized, washed with PBS, and incubated in $0.2 \%$ Triton $\mathrm{X}-100$ for $20 \mathrm{~min}$ at $37^{\circ} \mathrm{C}$. Then, DNA content was assessed by staining ethanol-fixed cells with propidium iodide and monitoring by FACS-Calibur (Becton Dickinson, Franklin Lakes, NJ, USA). The flow cytometry data were collected, and cell cycle distributions were analyzed with Cell Quest software (Becton Dickinson) as previously described (20).

Statistical analysis. All data are expressed as the mean \pm SD. Comparisons among multiple groups were made using one-way analyses of variance, followed by Fisher's protected least-significant-difference post-hoc test as previously described (21). A P-value $<0.05$ was considered statistically significant.

\section{Results}

Effects of fucoidan on HLF cell proliferation. The cell number did not differ between the control cells and those treated with $10 \mu \mathrm{g} / \mathrm{ml}$ fucoidan. However, treatment with 50 and $100 \mu \mathrm{g} / \mathrm{ml}$ fucoidan significantly and dose- and timedependently suppressed cell proliferation (Fig. 1A and B, $\mathrm{P}<0.0001)$. Cell number was $\sim 50 \%$ lower $96 \mathrm{~h}$ after treatment with $100 \mu \mathrm{g} / \mathrm{ml}$ fucoidan, as compared to the controls $\left(22.4 \pm 1.8 \times 10^{5}\right.$ vs. $0.9 \pm 0.2 \times 10^{5}$ cells/dish; Fig. $1 \mathrm{~A}$ and B). Cell viability was evaluated by trypan blue staining. Cell death was rarely observed beyond 96-h fucoidan treatment at any dose (data not shown).

Effects of fucoidan on AMPK expression and phosphorylation in HLF cells. After $24 \mathrm{~h}$ of treatment with PBS or $100 \mu \mathrm{g} / \mathrm{ml}$ fucoidan, AMPK expression and Ser172 phosphorylation were evaluated by immunoblotting. Although AMPK protein expression level did not differ between the controls and fucoidan-treated HLF cells, treatment with fucoidan enhanced Ser172 phosphorylation, as compared to control cells (Fig. 2). 

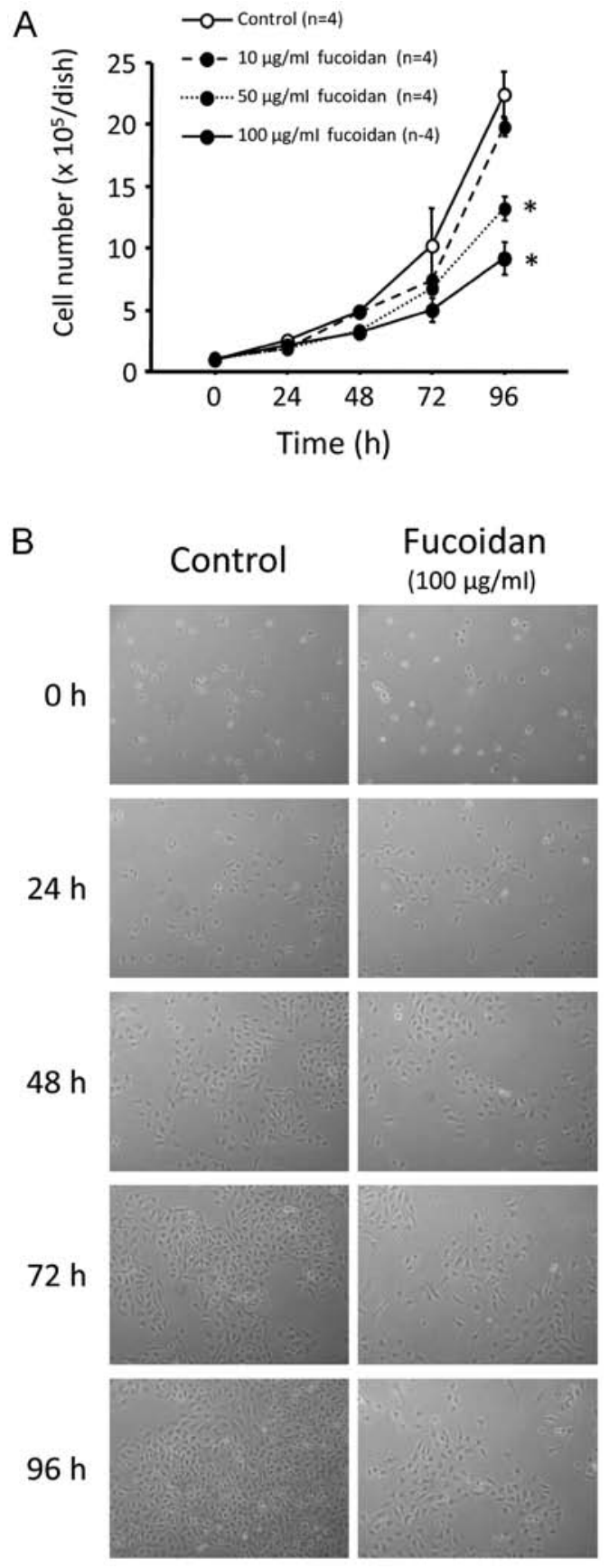

Figure 1. Effects of fucoidan on HLF cell proliferation. (A) HLF cells were treated with PBS (control) or fucoidan $(10,50$, or $100 \mu \mathrm{g} / \mathrm{ml})$. Cells were counted every $24 \mathrm{~h}$, up to $96 \mathrm{~h}$ after initial treatment. ${ }^{*} \mathrm{P}<0.0001$ as compared to the control. (B) Representative phase-contrast microscopic images of control and fucoidan (100 $\mu \mathrm{g} / \mathrm{ml})$-treated HLF cells $0,24,48,72$ and $96 \mathrm{~h}$ after treatment.

Effects of fucoidan on metabolism-associated molecule expression and phosphorylation in HLF cells. The effects of fucoidan on metabolism-associated molecules, such as TSC2/mTOR and eEF2/eEF2K were examined by immunoblotting. TSC 2 and mTOR expression was not altered by fucoidan treatment (Fig. 3). Furthermore, fucoidan treatment did not affect TSC2 Thr1462 or mTOR Ser2448 phosphorylation in HLF cells (Fig. 3). Similarly, eEF2K expression and EF2K Ser366 and eEF2 Thr56 phosphorylation were not altered by fucoidan treatment (Fig. 3).

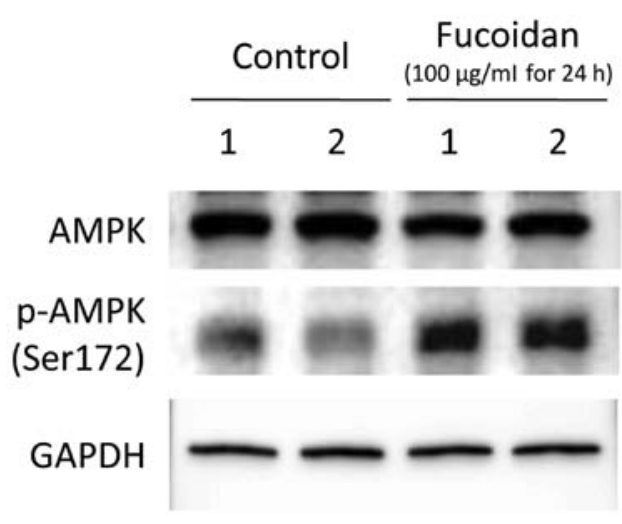

Figure 2. Effects of fucoidan on AMPK expression and phosphorylation. After $24 \mathrm{~h}$ of treatment with PBS (control) or fucoidan $(100 \mu \mathrm{g} / \mathrm{ml})$, AMPK and p-AMPK (Ser172) expression in HLF cells was examined by immunoblotting. GAPDH was used as a loading control.

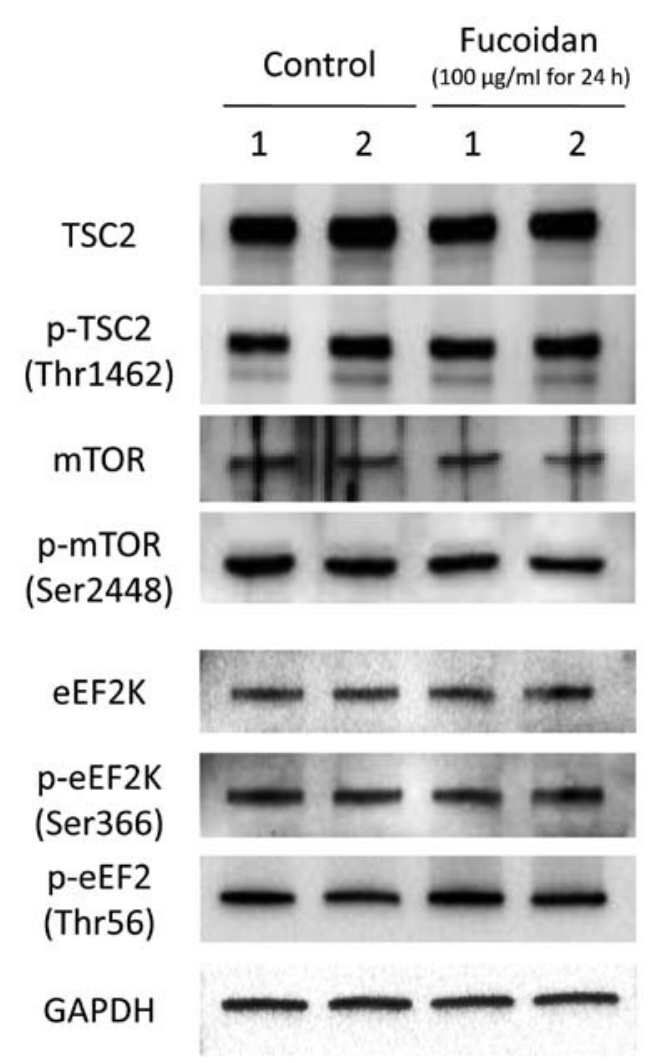

Figure 3. Effects of fucoidan on metabolism-associated molecule expression. After $24 \mathrm{~h}$ of treatment with PBS (control) or fucoidan $(100 \mu \mathrm{g} / \mathrm{ml})$, TSC2/mTOR and eEF2/eEF2K expression and phosphorylation in HLF cells were examined by immunoblotting. GAPDH was used as a loading control.

Effects of fucoidan on glucose and lipid metabolism-associated molecule expression in HLF cells. We next assessed the effects of fucoidan on the expression and phosphorylation of glucose and lipid metabolism-associated molecules, including GSK3 $\beta$, ACL and ACC, by immunoblotting. The expression of GSK3 $\beta$, and the phosphorylation of GSK $3 \beta$ at Ser9 and GSK3 $\alpha$ at Ser21 were not altered by fucoidan treatment (Fig. 4). Additionally, ACL expression and phosphorylation at Ser366 did not differ between the control and fucoidan-treated HLF cells (Fig. 4). Although there was no difference in ACC expression after 


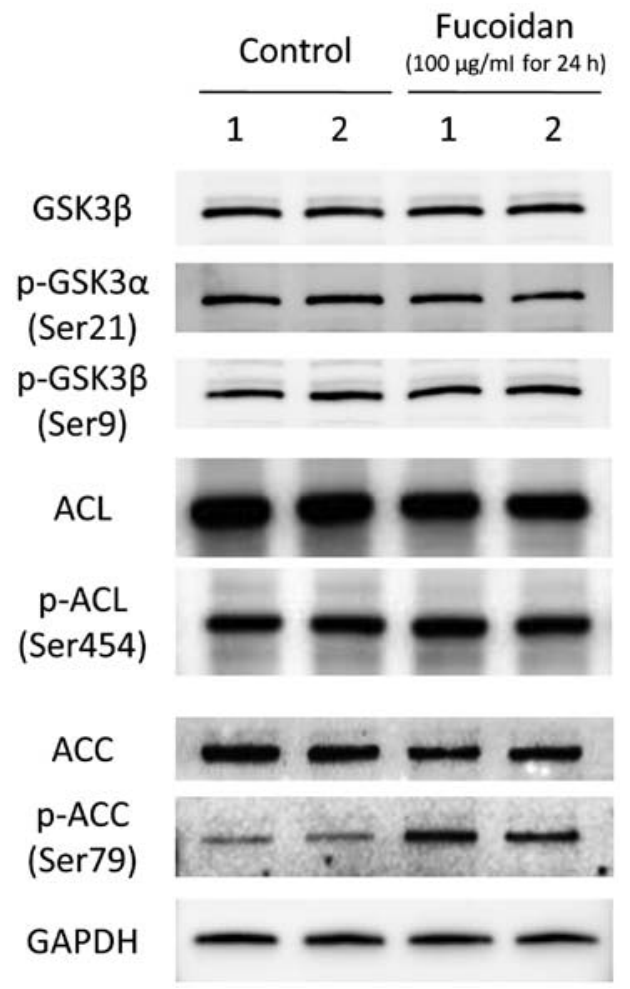

Figure 4. Effects of fucoidan on glucose and lipid metabolism-associated molecule expression and phosphorylation. After treatment with PBS (control) or fucoidan $(100 \mu \mathrm{g} / \mathrm{ml})$ for $24 \mathrm{~h}$, GSK3 $\beta$, GSK3 $\alpha$, ACL, and ACC expression and phosphorylation in HLF cells were examined by immunoblotting. GAPDH was used as a loading control.

fucoidan treatment, fucoidan enhanced ACC phosphorylation at Ser79 (Fig. 4).

Effects of fucoidan on cell cycle-associated molecule expression and phosphorylation in HLF cells. The effects of fucoidan on cell cycle-associated molecule expression and phosphorylation were examined by immunoblotting. Fucoidan did not alter p21, Rb and p16 expression in HLF cells (Fig. 5A). Furthermore, p53 expression and phosphorylation at Ser9 and Ser15 were similar in the control and fucoidan-treated HLF cells (Fig. 5B). In contrast, fucoidan decreased the expression of cyclin D1, CDK4 and CDK6 (Fig. 5B).

Effects of fucoidan on HLF cell cycle. At 24 h after initial treatment, there was no significant difference in cell cycle between the control and fucoidan-treated HLF cells (Fig. 6). However, $48 \mathrm{~h}$ after initial treatment, the percentage of cells in the G0/G1 phase was 57.4 and $29.3 \%$, that in the S phase was 18.9 and $57.0 \%$, and that in the G2/M phase was 23.7 and $13.7 \%$ in the control and fucoidan-treated HLF cells, respectively (Fig. 6). Thus, $100 \mu \mathrm{g} / \mathrm{ml}$ fucoidan treatment arrested HLF cells in the G1/S phase. Apoptosis was not observed in the control or fucoidan-treated HLF cells (Fig. 6).

\section{Discussion}

We demonstrated that fucoidan suppressed the proliferation of HLF cells, a poorly differentiated HCC. We also showed that fucoidan induces AMPK accompanied by ACC phos-

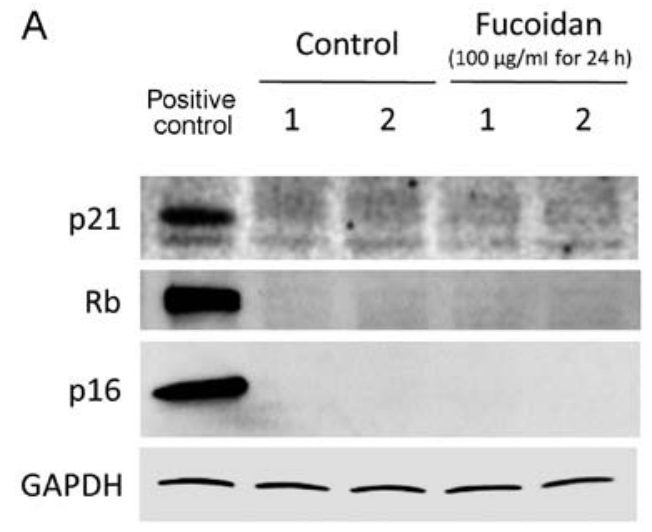

B
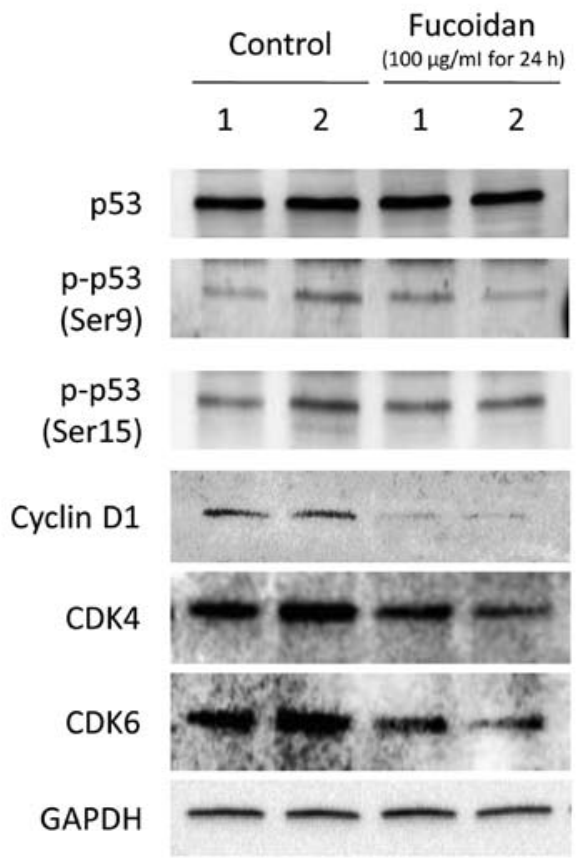

Figure 5. Effects of fucoidan on cell cycle-associated molecule expression and phosphorylation. The effects of fucoidan on (A) expression of $\mathrm{Rb}$, p21 and p16 and (B) expression of p53, cyclin D1, CDK4 and CDK6, and phosphorylation of p53 at Ser9 and Ser15 in HLF cells were examined by immunoblotting. GAPDH was used as a loading control.

phorylation and downregulation of cyclin D1, CDK4 and CDK6 expression. These findings suggest that fucoidan inhibits proliferation via AMPK-associated suppression of fatty acid synthesis and G1/S transition in HLF cells.

In this study, we showed that fucoidan suppressed proliferation, but not apoptosis, in HLF cells. In contrast, previous studies reported that fucoidan induces apoptosis in several human HCC cell lines, including HepG2, Huh7 and SMMC-7721 cells $(9,11,13,14)$. It is unclear why fucoidan did not induce apoptosis in HLF cells; however, one possibility is that there are different phenotypes between HCC cell lines. HLF cells were established from poorly differentiated HCC (22) and are resistant to apoptosis due to low tumor necrosis factor-related apoptosis-inducing ligand-receptor 2 expression (23). Thus, the mechanisms mediating fucoidan-induced proliferation suppression may differ depending on HCC phenotype.

AMPK is a central regulator of proliferation and exerts its effects via the regulation of metabolism and the cell 

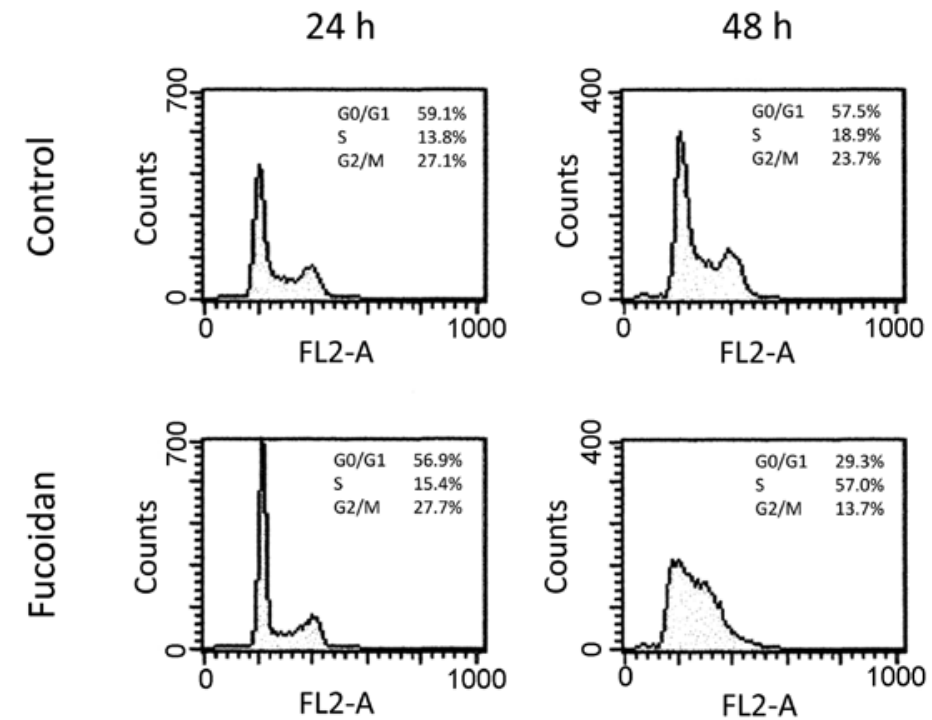

Figure 6. Effects of fucoidan on HLF cell cycle. After treatment with PBS (control) or fucoidan (100 $\mu \mathrm{g} / \mathrm{ml})$ for 24 or $48 \mathrm{~h}$, cell cycle progression was assessed based on DNA content by using flow cytometry.

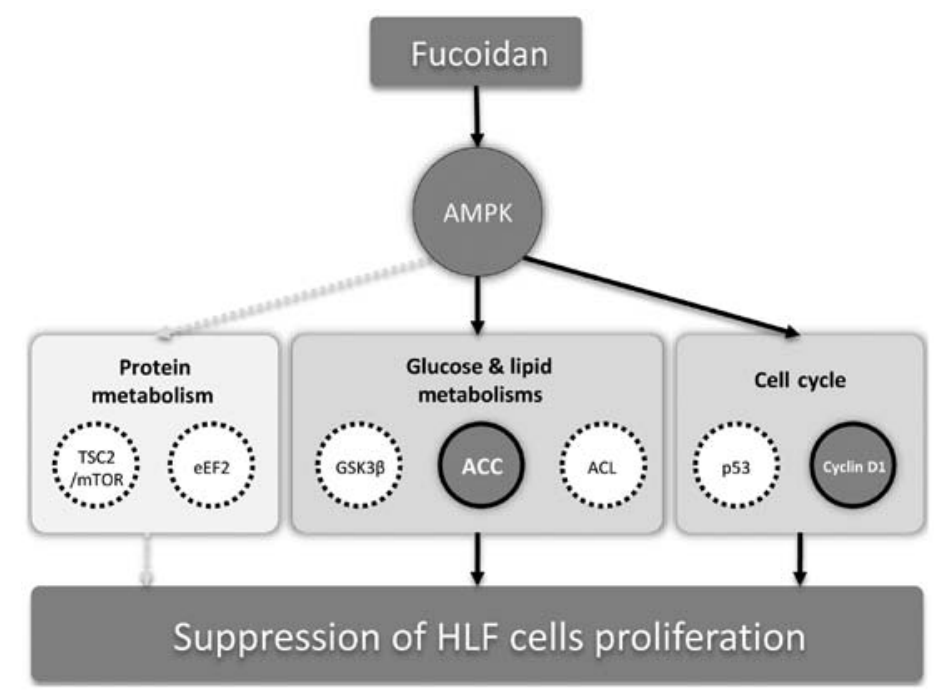

Figure 7. Proposed molecular mechanisms for fucoidan-induced suppression of HLF cell proliferation.

cycle. Thus, AMPK is a potential therapeutic target for cancer $(16,17)$. However, the effects of fucoidan on AMPK have not been reported. We first demonstrated that fucoidan phosphorylated AMPK in HLF cells. Although the mechanisms regulating fucoidan-induced AMPK activation remain unclear, AMPK is a member of the metabolite-sensing protein kinase family and is activated by depletion of intracellular ATP levels $(16,17)$. Fucoidan causes mitochondrial dysfunction in cancer cells (24). Since mitochondria produce ATP, fucoidan may activate AMPK through depletion of ATP via mitochondrial injury.

Phosphorylated AMPK inhibits protein synthesis, thereby suppressing cell proliferation through downregulation of the TCS2/mTOR (17) and eEF2/eEF2K pathways (25). Additionally, Lee et al reported that fucoidan inhibits human lung cancer cell migration and invasion via mTOR regulation (26). However, fucoidan did not affect the TCS2/mTOR or eEF2/eEF2K pathways in this study, suggesting that impairment of protein synthesis is not a major mechanism for fucoidan-induced suppression of HLF cell proliferation.

Phosphorylated AMPK also inhibits gluconeogenesis and lipogenesis, thereby suppressing proliferation through GSK3 $\beta$, ACL and ACC $(10,17,27)$. In this study, fucoidan did not affect the expression or phosphorylation of GSK3 $\beta$ and ACL; however, fucoidan induced ACC phosphorylation at Ser79. Phosphorylation at Ser79 inhibits malonyl-CoA production, an initial step of fatty acid synthesis (28). Various cancer cells exhibit a markedly increased rate of de novo fatty acid synthesis (17). Cancer cells activate fatty acid biosynthesis to sustain an increasing demand for phospholipids for membrane biogenesis (29). Moreover, high levels of arachidonic acid can promote breast cancer cell proliferation (30). Taken together, the suppression of fatty acid synthesis through AMPK-induced ACC phosphorylation may mediate fucoidan-induced proliferation suppression (Fig. 7). AMPK activation phosphorylates ACC, resulting in the suppression of 
prostate, breast and ovarian cancer cell proliferation (31-33), supporting our hypothesis.

AMPK is reported to regulate proliferation via the cell cycle machinery (17). Phosphorylated AMPK suppresses proliferation through p21, Rb, p16 and p53 (17). However, these molecules were not expressed in HLF cells, and fucoidan did not alter the expression or phosphorylation of p53. In contrast, fucoidan downregulated cyclin D1, CDK4 and CDK6 expression in HLF cells. Cyclin D1 is required for cell cycle G1/S transition (34) and G1/S arrest was seen in this study. Sikka et al reported that AMPK activation downregulates cyclin D1, CDK4 and CDK6, thereby inhibiting squamous cancer cell proliferation (35). Similar findings were also reported in myeloma cells (36). Moreover, Banafa et al demonstrated that fucoidan decreases cyclin D1 and CDK4 gene expression in human breast cancer MCF-7 cells (37). Thus, our findings, along with previous studies, suggest that AMPK-induces G1/S phase arrest via downregulation of cyclin D1, CDK4 and CDK6, thereby mediating fucoidan-induced suppression of HLF cell proliferation (Fig. 7).

In conclusion, we showed that fucoidan inhibited the proliferation of HLF cells, a poorly differentiated HCC. In addition, we demonstrated that fucoidan phosphorylated AMPK accompanied by phosphorylation of ACC and downregulates cyclin D1, CDK4 and CDK6 expression. These findings suggest that fucoidan suppresses proliferation via AMPK-mediated inhibition of fatty acid synthesis and cell cycle G1/S transition in HLF cells.

\section{Acknowledgements}

This study was supported, in part, by Health and Labour Sciences Research Grants for Research on Hepatitis from the Ministry of Health, Labour and Welfare of Japan.

\section{References}

1. Burroughs A, Hochhauser D and Meyer T: Systemic treatment and liver transplantation for hepatocellular carcinoma: Two ends of the therapeutic spectrum. Lancet Oncol 5: 409-418, 2004.

2. Kluger MD, Salceda JA, Laurent A, Tayar C, Duvoux C, Decaens T, Luciani A, Van Nhieu JT, Azoulay D and Cherqui D: Liver resection for hepatocellular carcinoma in 313 western patients: tumor biology and underlying liver rather than tumor size drive prognosis. J Hepatol: Dec 18, 2014 (Epub ahead of print).

3. Tanaka K and Sorai S: Hydrolysis of fucoidan by abalone liver alpha-L-fucosidase. FEBS Lett 9: 45-48, 1970.

4. Cui W, Zheng Y, Zhang Q, Wang J, Wang L, Yang W, Guo C, Gao W, Wang $X$ and Luo D: Low-molecular-weight fucoidan protects endothelial function and ameliorates basal hypertension in diabetic Goto-Kakizaki rats. Lab Invest 94: 382-393, 2014

5. Fitton JH: Therapies from fucoidan; multifunctional marine polymers. Mar Drugs 9: 1731-1760, 2011.

6. Boo HJ, Hong JY, Kim SC, Kang JI, Kim MK, Kim EJ, Hyun JW, Koh YS, Yoo ES, Kwon JM, et al: The anticancer effect of fucoidan in PC-3 prostate cancer cells. Mar Drugs 11: 2982-2999, 2013

7. Kim EJ, Park SY, Lee JY and Park JH: Fucoidan present in brown algae induces apoptosis of human colon cancer cells. BMC Gastroenterol 10: 96, 2010.

8. Xue M, Ge Y, Zhang J, Wang Q, Hou L, Liu Y, Sun L and Li Q: Anticancer properties and mechanisms of fucoidan on mouse breast cancer in vitro and in vivo. PLoS One 7: e43483, 2012

9. Min EY, Kim IH, Lee J, Kim EY, Choi YH and Nam TJ: The effects of fucodian on senescence are controlled by the p16INK4a-pRb and p14Arf-p53 pathways in hepatocellular carcinoma and hepatic cell lines. Int J Oncol 45: 47-56, 2014.
10. Yuan HD and Piao GC: An active part of Artemisia sacrorum Ledeb. suppresses gluconeogenesis through AMPK mediated GSK $3 \beta$ and CREB phosphorylation in human HepG2 cells. Biosci Biotechnol Biochem 75: 1079-1084, 2011.

11. Roshan S, Liu YY, Banafa A, Chen HJ, Li KX, Yang GX, He GY and Chen MJ: Fucoidan induces apoptosis of HepG2 cells by down-regulating p-Stat3. J Huazhong Univ Sci Technolog Med Sci 34: 330-336, 2014

12. Zhu C, Cao R, Zhang SX, Man YN and Wu XZ: Fucoidan inhibits the growth of hepatocellular carcinoma independent of angiogenesis. Evid Based Complement Alternat Med 2013: 692549,2013

13. Nagamine T, Hayakawa K, Kusakabe T, Takada H, Nakazato K, Hisanaga $\mathrm{E}$ and Iha M: Inhibitory effect of fucoidan on Huh7 hepatoma cells through downregulation of CXCL12. Nutr Cancer 61: 340-347, 2009.

14. Fukahori S, Yano H, Akiba J, Ogasawara S, Momosaki S, Sanada S, Kuratomi K, Ishizaki Y, Moriya F, Yagi M, et al: Fucoidan, a major component of brown seaweed, prohibits the growth of human cancer cell lines in vitro. Mol Med Rep 1: 537-542, 2008.

15. Hardie DG: AMPK - sensing energy while talking to other signaling pathways. Cell Metab 20: 939-952, 2014.

16. Lacher MD, Pincheira R, Zhu Z, Camoretti-Mercado B, Matli M, Warren RS and Castro AF: Rheb activates AMPK and reduces p27Kip1 levels in Tsc2-null cells via mTORC1-independent mechanisms: Implications for cell proliferation and tumorigenesis. Oncogene 29: 6543-6556, 2010.

17. Motoshima H, Goldstein BJ, Igata M and Araki E: AMPK and cell proliferation - AMPK as a therapeutic target for atherosclerosis and cancer. J Physiol 574: 63-71, 2006.

18. Hashimoto O, Shinkawa M, Torimura T, Nakamura T, Selvendiran K, Sakamoto M, Koga H, Ueno T and Sata M: Cell cycle regulation by the Weel inhibitor PD0166285, pyrido [2,3-d] pyimidine, in the B16 mouse melanoma cell line. BMC Cancer 6: 292, 2006.

19. Kawaguchi T, Yoshida T, Harada M, Hisamoto T, Nagao Y, Ide T, Taniguchi E, Kumemura H, Hanada S, Maeyama M, et al: Hepatitis $C$ virus down-regulates insulin receptor substrates 1 and 2 through up-regulation of suppressor of cytokine signaling 3. Am J Pathol 165: 1499-1508, 2004.

20. Selvendiran K, Koga H, Ueno T, Yoshida T, Maeyama M, Torimura T, Yano H, Kojiro M and Sata M: Luteolin promotes degradation in signal transducer and activator of transcription 3 in human hepatoma cells: An implication for the antitumor potential of flavonoids. Cancer Res 66: 4826-4834, 2006.

21. Kawaguchi T, Sakisaka S, Mitsuyama K, Harada M, Koga H, Taniguchi E, Sasatomi K, Kimura R, Ueno T, Sawada N, et al: Cholestasis with altered structure and function of hepatocyte tight junction and decreased expression of canalicular multispecific organic anion transporter in a rat model of colitis. Hepatology 31: $1285-1295,2000$.

22. Matsumoto A, Ono M, Fujimoto Y, Gallo RL, Bernfield M and Kohgo Y: Reduced expression of syndecan-1 in human hepatocellular carcinoma with high metastatic potential. Int J Cancer 74: 482-491, 1997.

23. Yamamoto T, Nagano H, Sakon M, Wada H, Eguchi H, Kondo M, Damdinsuren B, Ota H, Nakamura M, Wada H, et al: Partial contribution of tumor necrosis factor-related apoptosis-inducing ligand (TRAIL)/TRAIL receptor pathway to antitumor effects of interferon-alpha/5-fluorouracil against hepatocellular carcinoma. Clin Cancer Res 10: 7884-7895, 2004.

24. Park HY, Kim GY, Moon SK, Kim WJ, Yoo YH and Choi YH: Fucoidan inhibits the proliferation of human urinary bladder cancer T24 cells by blocking cell cycle progression and inducing apoptosis. Molecules 19: 5981-5998, 2014.

25. Leprivier G, Remke M, Rotblat B, Dubuc A, Mateo AR, Kool M Agnihotri S, El-Naggar A, Yu B, Somasekharan SP, et al: The eEF2 kinase confers resistance to nutrient deprivation by blocking translation elongation. Cell 153: 1064-1079, 2013.

26. Lee H, Kim JS and Kim E: Fucoidan from seaweed Fucus vesiculosus inhibits migration and invasion of human lung cancer cell via PI3K-Akt-mTOR pathways. PLoS One 7: e50624, 2012.

27. Migita T, Okabe S, Ikeda K, Igarashi S, Sugawara S, Tomida A, Taguchi R, Soga T and Seimiya H: Inhibition of ATP citrate lyase induces an anticancer effect via reactive oxygen species: AMPK as a predictive biomarker for therapeutic impact. Am J Pathol 182: 1800-1810, 2013.

28. Hopkins TA, Dyck JR and Lopaschuk GD: AMP-activated protein kinase regulation of fatty acid oxidation in the ischaemic heart. Biochem Soc Trans 31: 207-212, 2003. 
29. Scaglia N, Chisholm JW and Igal RA: Inhibition of stearoylCoA desaturase-1 inactivates acetyl-CoA carboxylase and impairs proliferation in cancer cells: Role of AMPK. PLoS One 4: e6812, 2009.

30. Chang NW, Wu CT, Chen DR, Yeh CY and Lin C: High levels of arachidonic acid and peroxisome proliferator-activated receptoralpha in breast cancer tissues are associated with promoting cancer cell proliferation. J Nutr Biochem 24: 274-281, 2013.

31. Hadad SM, Hardie DG, Appleyard V and Thompson AM: Effects of metformin on breast cancer cell proliferation, the AMPK pathway and the cell cycle. Clin Transl Oncol 16: 746-752, 2014.

32. Lin VC, Tsai YC, Lin JN, Fan LL, Pan MH, Ho CT, Wu JY and Way TD: Activation of AMPK by pterostilbene suppresses lipogenesis and cell-cycle progression in $\mathrm{p} 53$ positive and negative human prostate cancer cells. J Agric Food Chem 60: 6399-6407, 2012.

33. Rattan R, Giri S, Hartmann LC and Shridhar V: Metformin attenuates ovarian cancer cell growth in an AMP-kinase dispensable manner. J Cell Mol Med 15: 166-178, 2011.
34. Santra MK, Wajapeyee N and Green MR: F-box protein FBXO31 mediates cyclin D1 degradation to induce G1 arrest after DNA damage. Nature 459: 722-725, 2009.

35. Sikka A, Kaur M, Agarwal C, Deep G and Agarwal R: Metformin suppresses growth of human head and neck squamous cell carcinoma via global inhibition of protein translation. Cell Cycle 11: 1374-1382, 2012.

36. Zi FM, He JS, Li Y, Wu C, Yang L, Yang Y, Wang LJ, He DH, Zhao Y, Wu WJ, et al: Metformin displays anti-myeloma activity and synergistic effect with dexamethasone in in vitro and in vivo xenograft models. Cancer Lett 356: 443-453, 2015.

37. Banafa AM, Roshan S, Liu YY, Chen HJ, Chen MJ, Yang GX and He GY: Fucoidan induces G1 phase arrest and apoptosis through caspases-dependent pathway and ROS induction in human breast cancer MCF-7 cells. J Huazhong Univ Sci Technolog Med Sci 33: 717-724, 2013. 